Supporting Information

\title{
Bismuth Anchored on MWCNTs with Controlled Ultrafine Nanosize Enables High-Efficient Electrochemical Reduction of Carbon Dioxide to Formate Fuel
}

\author{
Xia Zhang, ${ }^{\mathrm{a}, \mathrm{b}}$, Jing $\mathrm{Fu}^{\mathrm{c}}$, Yuyu Liu ${ }^{\mathrm{d}}$, Xiao-Dong Zhou ${ }^{\mathrm{e}}$, Jinli Qiao ${ }^{\mathrm{b} *}$
}

${ }^{a}$ Henan Key Laboratory of Water Pollution Control and Rehabilitation, Henan University of Urban Construction, Longxiang Avenue, Pingdingshan 467000, China

${ }^{\mathrm{b}}$ Shanghai Institute of Pollution Control and Ecological Security, Shanghai 200092, College of Environmental Science and Engineering, Donghua University, 2999 Ren’min North Road, Shanghai 201620, China. E-mail: qiaojl@dhu.edu.cn

'School of Materials Science and Engineering, Tongii University, Shanghai, 201804, China

dnstitute of Sustainable Energy, Shanghai University, 99 Shangda Road, Shanghai 200444, China

${ }^{e}$ Department of Chemical Engineering, University of Louisiana at Lafayette, Lafayette, LA 70504, USA

Number of page: 8

Number of figure: 3

Number of table: 1 


\section{EXPERIMENTAL SECTION}

Materials

The raw functionalized multi-walled carbon nanotubes with a carboxylic acid group (purity $>98 w t \%$ ) were provided by Timesnano (Chengdu, China). Bismuth nitrate pentahydrate $\left(\mathrm{Bi}\left(\mathrm{NO}_{3}\right)_{3} \quad 5 \mathrm{H}_{2} \mathrm{O}\right)$, Sodium borohydride $\left(\mathrm{NaBH}_{4}\right)$, trisodium citrate dehydrate $\left(\mathrm{C}_{6} \mathrm{H}_{5} \mathrm{Na}_{3} \mathrm{O}_{7} \quad 2 \mathrm{H}_{2} \mathrm{O}\right)$, nitric acid $\left(\mathrm{HNO}_{3}, 98\right.$ wt.\%), potassium bicarbonate $\left(\mathrm{KHCO}_{3}\right)$, isopropyl alcohol $\left(\mathrm{C}_{3} \mathrm{H}_{8} \mathrm{O}\right)$ were all purchased from Sinopharm Chemical Reagent Co., Ltd. (Shanghai, China). All of the chemicals were used without further purification. All the aqueous solutions were prepared using deionized (DI) water.

Physical Characterization

The X-ray diffraction (XRD) patterns were obtained using X-ray diffraction (D/max-2550 PC, Japan) with a $\mathrm{Cu}-\mathrm{Ka}_{1}$ radiation source $(\lambda=1.54056 \AA)$. The morphologies and microstructures of obtained catalysts were characterized by a high resolution transmission electron microscope (HR-TEM, JEM-2100F, Japan). The X-ray photoelectron spectroscopy (XPS) measurements were carried out using an Escalab 250Xi (USA) system. The Bi content analysis of prepared catalysts was carried out on an inductively coupled plasma-optical emission spectrometry (ICP-OES, Leeman Prodigy, USA).

Electrochemical Measurments

A 660E Electrochemical Analyzer ( $\mathrm{CH}$ Instruments) was used for all the electrochemical reduction of $\mathrm{CO}_{2}$ experiments under room temperature and ambient pressure. Unless otherwise stated, the electrochemical performance of the prepared catalysts was studied in $0.5 \mathrm{M} \mathrm{KHCO}_{3}$ saturated with $\mathrm{CO}_{2}(\mathrm{pH}=7.3)$. A platinum (Pt) wire was used as the counter electrode. The carbon paper $(2 \mathrm{~cm} \times 2 \mathrm{~cm})$ coated with the catalyst $\left(3.0 \pm 0.1 \mathrm{mg} \mathrm{cm}^{-2}\right)$ was used as the working electrode. Potentials $\mathrm{E}$ were measured against a saturated calomel reference electrode (SCE). Electrolyses were 
performed in a gas-tight two-compartment electrochemical cell separated by a piece of proton exchange membrane (Nafion ${ }^{\circledR} 117$, DuPont). The solution was purged with $\mathrm{N}_{2}$ (99.999\%) for 30 min before all the electrolysis. Before the $\mathrm{CO}_{2}$ reduction experiments, the solution in the cathodic compartment was bubbled with $\mathrm{CO}_{2}$ (99.99\%) for $30 \mathrm{~min}$, and $\mathrm{CO}_{2}$ was continuously fed during the electrolysis.

\section{Reduction Products Analysis}

The gas chromatograph (GC1120, Shanghai Sunny Hengping Scientific Instrument Co. Ltd) equipped with a thermal conductivity detector (TCD) and a flame ionization detector (FID) was used to analyze the gas product. An ion chromatography (IC1820, Shanghai Sunny Hengping Scientific Instrument Co. Ltd) was employed to quantify the liquid products. The Faradaic efficiency (FE) of the products was calculated according to the Equation S1 and Equation S2.

The Faradaic efficiency (FE) of formate production $\left(\mathrm{FE}_{\mathrm{HCOO}}{ }^{-}\right)$was calculated as below:

$$
\mathrm{FE}_{\mathrm{HCOO}^{-}}=\frac{2 m F}{Q} \quad \text { Equation S1 }
$$

Where 2 is the electron transfer number, $\mathrm{m}$ is the moles of formate produced during the electrolysis, $Q$ is the total charge during the electrolysis (C), $F=96485 \mathrm{C} \mathrm{mol}^{-1}$.

The Faradaic efficiency for the products of $\mathrm{CO}$ and $\mathrm{H}_{2}$ production ( $F E_{\mathrm{CO}}$ or $F E_{\mathrm{H} 2}$ ) was as below ${ }^{1}$ :

$$
F E_{\mathrm{CO} / \mathrm{H} 2}=\frac{10^{-3} \mathrm{mv} \% \mathrm{FG}}{60 \mathrm{RTi}} P \quad \text { Equation S2 }
$$

Where $v \%$ is the volume concentration of $\mathrm{CO} / \mathrm{H}_{2}$ in the collected gases from the headspace of the cell, $G$ is the $\mathrm{CO}_{2}$ gas flow rate $\left(\mathrm{mL} \min ^{-1}\right), m$ is the number of electrons transferred for the products $\mathrm{CO}$ and $\mathrm{H}_{2}$ (here $\left.\mathrm{m}=2\right), i$ is the current $(\mathrm{mA}), P=$ $1.01 \times 10^{5} \mathrm{~Pa}, T=273.15 \mathrm{~K}, R=8.314 \mathrm{~J} \mathrm{~mol}^{-1} \mathrm{~K}^{-1}, F=96485 \mathrm{C} \mathrm{mol}^{-1}$. 


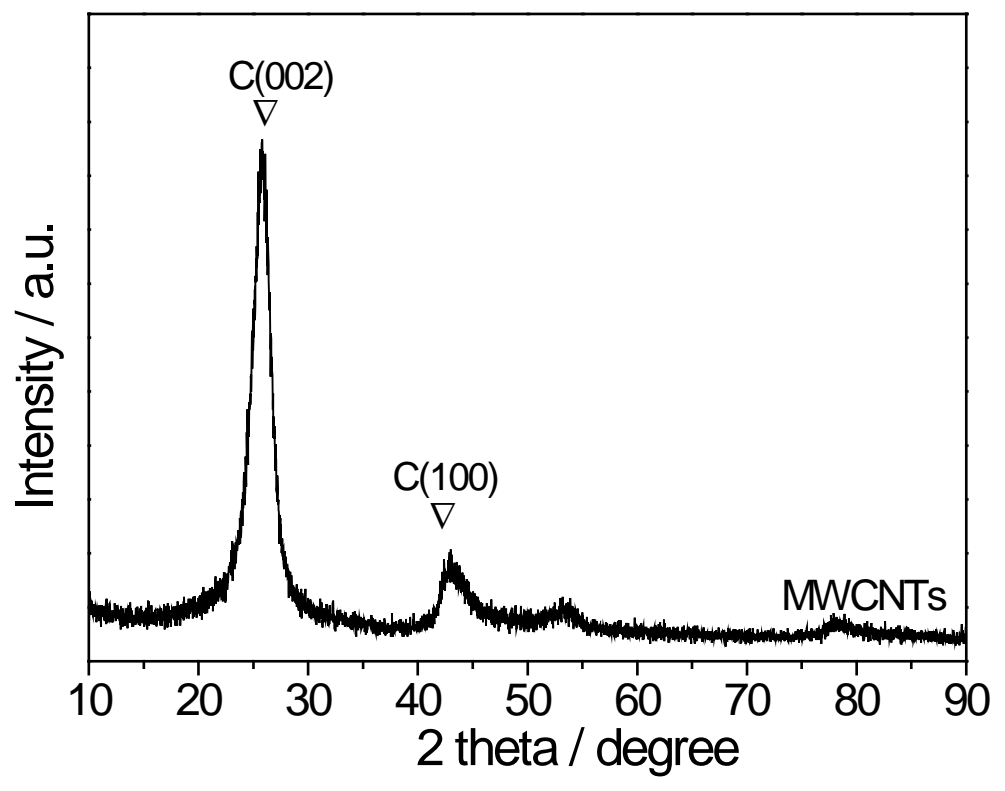

Figure S1 XRD patterns of MWCNTs support. 


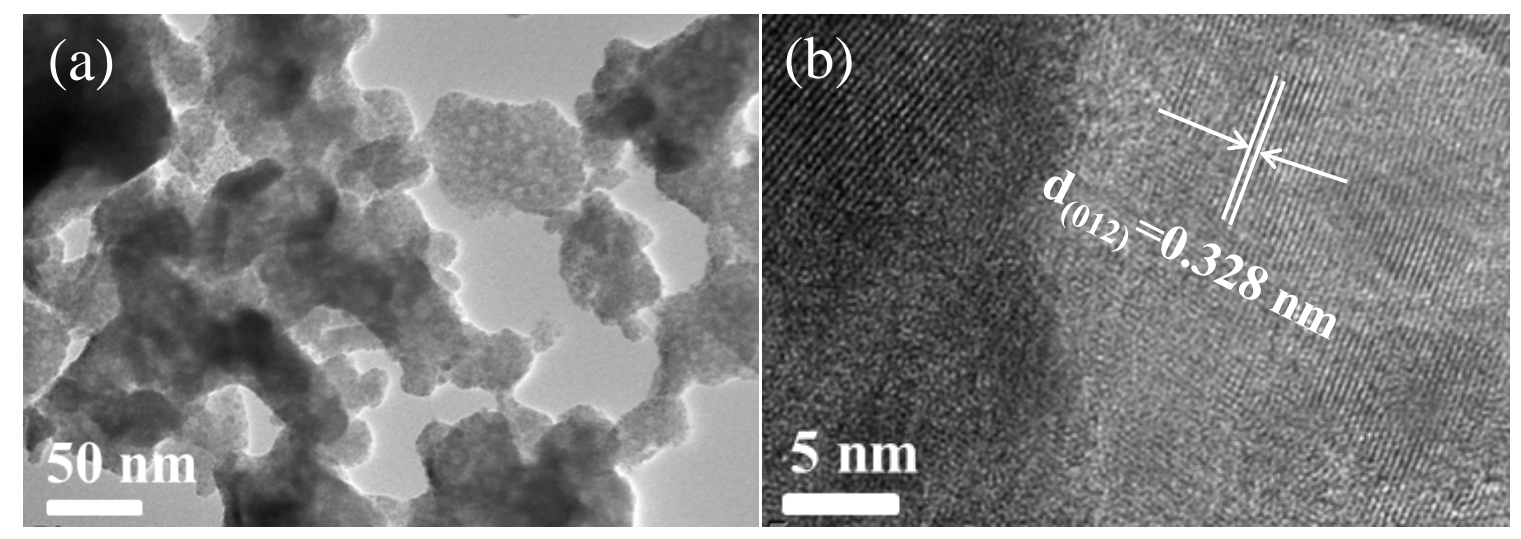

Figure S2 (a) TEM image of $\mathrm{Bi}_{\text {blank }}$; (b) HRTEM image of $\mathrm{Bi}_{\text {blank }}$. 


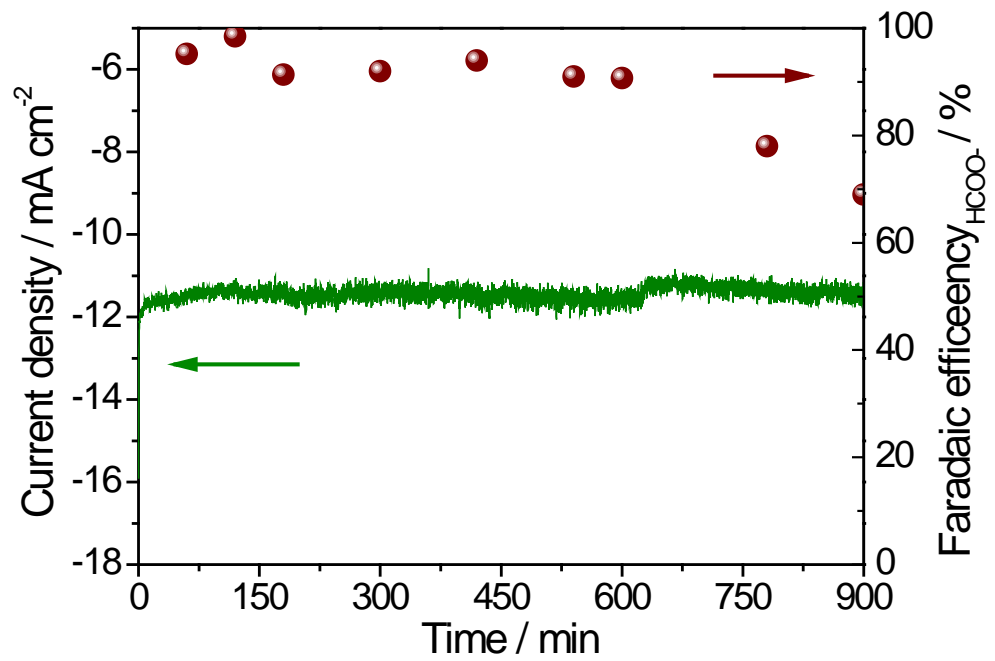

Figure S3 Stability of Bi NP@MWCNTs, Current density and Faradaic efficiency for formate at different time; a long-time operation for 15 hours at $-1.5 \mathrm{~V}$ vs. SCE. 
Table S1 Faradaic efficiencies and current densities during constant potential electrolysis at various catalysts

\begin{tabular}{|c|c|c|c|c|c|c|c|c|}
\hline \multirow[b]{2}{*}{ sample } & \multicolumn{4}{|c|}{-1.45 V vs. SCE } & \multicolumn{4}{|c|}{$-1.50 \mathrm{~V}$ vs. SCE } \\
\hline & $\begin{array}{c}F E_{\text {HCOO- }} \\
(\%)\end{array}$ & $\begin{array}{c}F E_{\mathrm{CO}} \\
(\%)\end{array}$ & $\begin{array}{c}F E_{\mathrm{H} 2} \\
(\%)\end{array}$ & $\begin{array}{c}\text { Current } \\
\text { density } \\
\left(\mathrm{mA} \mathrm{cm}^{-2}\right)\end{array}$ & $\begin{array}{c}F E_{\text {HCOO- }} \\
(\%)\end{array}$ & $\begin{array}{c}F E_{\mathrm{CO}} \\
(\%)\end{array}$ & $\begin{array}{c}F E_{\mathrm{H} 2} \\
(\%)\end{array}$ & $\begin{array}{c}\text { Current } \\
\text { density } \\
\left(\mathrm{mA} \mathrm{cm}^{-2}\right)\end{array}$ \\
\hline MWCNTs & - & 5.2 & 2.4 & -0.7 & - & 7.5 & 5.8 & -1.0 \\
\hline Bi NP@MWCNTs & 93.4 & - & 4.2 & -7.9 & 95.2 & - & 3.0 & -10.7 \\
\hline $\mathrm{Bi}_{\text {blank }}$ & 86 & 4.5 & 10.3 & -3.0 & 90.75 & 3.0 & 9.2 & -6.6 \\
\hline
\end{tabular}




\section{References}

(1) Guo, X.; Zhang, Y.; Deng, C.; Li, X.; Xue, Y.; Yan, Y. M.; Sun, K. Composition dependent activity of $\mathrm{Cu}-\mathrm{Pt}$ nanocrystals for electrochemical reduction of $\mathrm{CO}_{2}$. Chem. Commun. 2015, 51 (7), 1345-1348,DOI:10.1039/c4cc08175g. 